\title{
A UTILIZAÇÃO DE CARTÕES VIRTUAIS DE APRENDIZAGENS EM PROJETO DE AVALIAÇÃO POR PARES
}

\author{
SOBRAL /CE JUNHO/2018 \\ JoãoJosé Saraiva da Fonseca - Uninta - joaojosefonseca@gmail.com \\ Sonia Maria Henrique Pereira da Fonseca - Uninta - soniafonseca@uninta.edu.br
}

Tipo: Relato de Experiência Inovadora (EI)

Categoria: Pesquisa e Avaliação

Setor Educacional: EDUCAÇÃO SUPERIOR

\begin{abstract}
RESUMO
O objetivo da pesquisa em andamento de que se apresentam os primeiros resultados, propõe-se analisar a contribuição do uso de cartões virtuais de aprendizagem em projetos de avaliação por pares, para uma avaliação formativa, que adote simultâneamente de estimulo à formação de comunidades de prática pelo uso da gameficação. O estudo impirico atualmente em andamento, envolve a observação da avaliação do processo de aprendizagens em Ambiente Virtual e a realização de grupo focal com professores e estudantes e os primeiros resultados apontam para o aprofundamento da reflexão dos professores face à dificuldade de criar as condições para a avaliação e por outro lado, uma certa expectativa dos estudantes quanto à sua utilização na prática de avaliação de seus pares.
\end{abstract}

Palavras-chave: Avaliação, gamificação, avaliação por pares, avaliação formativa, cartão virtual de aprendizagens 


\section{Introdução}

?O presente texto procura apresentar uma pesquisa em desenvolvimento de utilização de cartões virtuais de aprendizagem associado à avaliação por pares em um projeto de Pós-Gradução Latu Sensu a distância. O documentocomeça com uma breve visão geral do propósito da avaliação de pares, depois descreve os motivos para o uso de paresavaliação no projeto de Pós-Gradução Latu Sensu a distânciae apresenta os requisitos construídos para a utilização de cartões virtuais de aprendizagem no projeto de avaliação porpares e descreve alguns dos primeiros resultados da aplicação na prática da proposta do curso. O presente documento será útil para equipes interessadas na mecânica da implementação de avaliação por pares em cursos de educação a distância, com a particular referência do Cartão Virtual de Aprendizagem.

\section{Referencial teórico}

?A avaliação por pares é amplamente utilizada nas práticas de ensino e aprendizagem, possibilitando desenvolver competências de alto nível, como a capacidade de avaliar e dar um feedback que justifique a avaliação realizada. Por outro lado, serve o propósito de possibilitar ao estuante incrementar melhorias em seu trabalho com base nos comentários recebidos de seus pares. ?O conceito de avaliação por pares remete para a ideia de um arranjo em que indivíduos avaliam a quantidade, nível, valor, valor, qualidade ou sucesso dos produtos ou resultados da aprendizagem de pares com status semelhante. (Hall e Buzwell, 2012). ?A avaliação de pares pode ser aplicada para: Recompensar o esforço individual, uma vez que a avaliação externa do professor nem sempre reflete de forma adequada a contribuição individual de cada estudante (Conway, et al., 1993); - Aumentar a responsabilidade dos alunos para a aprendizagem, para evitar receber uma avaliação negativa dos pares ou então de receber reclamações dos mesmos em função da avaliação realizada (Hall e Buzwell, 2012); - Empoderar os estudantes com a capacidade de avaliar e promover reflexões vivenciadas a propósito de aspetos éticos, o que resultará em maiores níveis de satisfação dos estudantes (Hall e Buzwell, 2012).

?O Cartão Virtual de Aprendizagem recupera a ideia de portófilo (MACHADO; QUADROS; BENVENUTTI, 2016).e da gamificação, possibililitando que o estudante construa um percursos consolidado de aprendizagem de documentos elaborados a partir dos referenciais de avaliação propostos e os possa permamentente melhorar, bem como se sinta motivado em assumir o desafio de estudar procurando melhorar a sua performance face ao outro, visto não como um opositor, nas como um parceiro de caminhada. ?Para Machado; Quadros; Benvenutti (2016), o portfólio consiste na 
compilação dos trabalhos realizados pelos alunos no decorrer de um ciclo de aprendizagem. Tem como eixo norteador o encontro entre alunos e docentes em fóruns de discussão e ou encontros presenciais, nos quais se discute, crítica, apresentam propostas, se reforçam conteúdos considerados significativos, se apresentam práticas vividas emcontextos escolares formais e/ou informais. ?A Gamificação de acordo com Vianna et al.(2013) contempla o uso de mecanismos de jogos, em situações que fogem do contexto do jogo, para a motivação e o engajamento ds estudantes.

O cartão virtual na proposta de avaliação por pares dos cursos de Pós-Graduação Lato Sensu a distância

?A proposta de avaliação por pares dos Cursos de Pós-Graduação Lato Sensu considerou como referencial as três estratégias apontadas por Conway et al (1993) para a avaliação por pares. O modelo pedagógico para a avaliação das aprendizagens nos cursos de Pós-Graduação Lato-Sensu na modalidade de educação a distância do Centro Universitário INTA - UNINTA EAD, foi concebido considerando a particularidade da existência de Cartão Virtual de Aprendizagens do Estudante (CVA). O CVA tem como objetivo fundamental contribuir para a valorização contínua do percurso pessoal das aprendizagens do estudante. O Cartão Virtual de Aprendizagens do estudante permite que invista na sua aprendizagem ao longo do seu percurso acadêmico, creditando as atividades que realizar. Estimula-se também que o estudante assuma um papel de protagonista, na avaliação enquanto um conjunto de procedimentos e ações que, em contexto de ensino e aprendizagem, determinam o grau de aquisição de um conjunto de competências, previamente estabelecidos nos objetivos da aprendizagem de uma determinada disciplina. A avaliação das aprendizagens assume um caráter de avaliação formativa, considerando a realização, de um conjunto de atividades propostas ao estudante ao longo do processo de ensino e aprendizagem, visando que este possa ajuizar dos seus progressos e selecionar as atividades que deseja realizar.

Em cada disciplina o estudante terá como atividades de avaliação:

+ Duas Avaliações Formativas (AF1 e AF2), dois p-folios eum t-folio, disponibilizados de acordo com o calendário acadêmico. A sequência de atividades será Avaliação Formativa 1 (AF1) e p-fólio 1 (PF1); Atividade Formativa 2 (AF2) e p-fólio 2 (PF2) e tfólio (TF). Fóruns de discussão ocorrerão paralelamente à disciplina.

Tabela 1. Atividades de avaliação durante o processo de ensino e aprendizagem

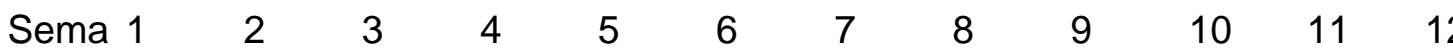


na

Ativida

AF1

des

PF1

AF2

PF2

TF

AP1

AP2

AP3

Fonte: Autoria própria

Cada Avaliação Formativa (AF1 e AF2) engloba a disponibilização pelo professor do curso de cinco atividades. Entre essas as cinco atividades o estudante escolhe duas para realizar e postar no AVA para apreciação e avaliação pelos colegas usando a ferramenta do Moodle "Laboratório de avaliação" (Workshop). Utilizando a mesma ferramenta, o estudante analisa as atividades de Avaliação Formativa de dois colegas a partir de critérios definidos por ele que justificará no p-fólio (PF1 e PF2). A nota do estudante em cada Atividade Formativa (AF1 e AF2) é resultado da média entre a nota atribuída por ele e a nota dos colegas que no AVA avaliam o seu trabalho. A nota da Avaliação Formativa corresponde a 50\% da nota da AP1 e da AP2.

O Plano de ensino deverá definir o tipo de trabalho a solicitar em cada disciplina como Atividade Formativa (AF1 e AF2), podendo contemplar, por exemplo:

- resolução de problemas

Cada estudante trabalha na solução de um problema e, em seguida, é convidado a compartilhar sua(s) solução(ões) com todo o grupo e discutir as diferenças entre as soluções propostas, em fórum de discussão ou blog.

- estudo de caso

O estudante recebe um exemplo de um caso e analisa o cenário do mesmo de acordo com a informação disponibilizada no conteúdo apresentado no curso. O estudante apresenta suas descobertas a todo o grupo, em fórum de discussão ou blog. $O$ estudante pode relatar casos a partir de suas experiências e compartilhar os mesmos para discussão e análise. Os casos relatados poderão ser selecionados para a construção de um portfólio. 
- síntese de leituras propostas

- debates

O estudante participa em debates com temática definida pelo professor, apresentando argumentos os fundamentados que considerar poderem contribuir para a sua aprendizagem.

- relatórios

- O estudante constrói de textos colaborativos com temática definida pelo professor, utilizando a ferramenta do Moodle wiki.

- O estudante apresenta dúvidas sobre pormenores do conteúdo do material didático que o estudante deseje ver esclarecidos e resposta pelos colegas, em fórum de discussão.

- O estudante busca de informação que possa apresentar e justificar a relação entre o conteúdo da disciplina e a prática, com a postagem dos resultados e debate em fórum de discussão.

- O estudante elabora um questionário sobre temáticasdefinida pelo professor, com perguntas verdadeiras ou falsasou de escolha múltipla, visando a coleta de informação que permita a compreensão do conteúdo estudado

- O estudante elabora criar mapa conceitual com base em temáticas definidas pelo professor

- O estudante produz vídeos (com celular) ou realiza apresentações multimídia, visando traduzir o conteúdo apresentado em outras linguagens.

+ Dois portfólios parciais - p-fólios (PF1 e PF2) nos quais o estudante numa proposta de auto-avaliação, refletirá sobre a temática das Atividades Formativas (AF1 e AF2) que avaliou e justificará a nota atribuída às mesmas e os respetivos critérios de avaliação. Cada um dos p-fólios contará com 50\% para a AP1 e AP2.

+ Espaços de fórum associados a cada Atividade Formativa e moderados pelos estudantes permitem que possam discutir as leituras, trocar ideias sobre as atividades realizadas, estimulando aprendizagens colaborativas e a pertença a uma comunidade 
de estudo.

Os critérios de participação do estudante no fórumdeverão atender aos referenciais:

A. O estudante durante as suas participações e comentários às postagens dos colegas, contribuiu com base em leituras e experiências recolhidas para além do conteúdo da disciplina, acrescentando elementos novos e inovadores para discussão. Respeitou durante as suas intervenções as normas da netiqueta, os direitos autorais e da ABNT. $(10,0)$

B. O estudante se baseou no conteúdo da disciplina e nas próprias reflexões para realizar as suas intervenções e comentar as participações dos colegas. Respeitou durante as suas postagens as normas da netiqueta, dos direitos autorais e da ABNT. $(8,0)$

C. O estudante se baseou no conteúdo da disciplina e nas próprias reflexões para realizar as suas intervenções, não interagindo com os colegas. $(5,0)$

D. O estudante não participou. $(0,0)$

+ Portfólio total - t-fólio (TF) por intermédio do qual o estudante refletirá numa proposta de auto-avaliação, sobre a temática das Atividades Formativas (AF1 e AF2) que realizou e avaliou, bem como sobre as participações que teve nos fóruns 1 e 2 e fará uma síntese das aprendizagens realizadas na disciplina.

Critérios para a avaliação do portfólio total (f-fólio):

A. O t-fólio é coerente com a atividade que o estudante realizou e avaliou, bem como sobre as participações que teve nos fórums 1 e 2, para além de realizar uma síntese das aprendizagens realizadas na disciplina $(10,0)$.

B. O t-fólio é coerente com a atividade que o estudante realizou e avaliou, bem como sobre as participações que teve nos fóruns 1 e 2. $(8,0)$.

C. A. O t-fólio é coerente com a atividade que o estudante realizou e avaliou, bem como sobre as participações que teve nos fórums 1 e 2, para além de realizar uma síntese das aprendizagens realizadas na disciplina e apresenta problemas, contudo não respeitou os direitos autorais e da ABNT. $(5,0)$ 
D. O t-fólio não encontra respaldo nas orientações/instruções. $(3,0)$

E. O estudante não executou o t-fólio. $(0,0)$

A nota do t-fólio será considerada para efeitos de AP3 e contribuirá como $60 \%$ para o Cartão Virtual de Aprendizagens do estudante (CVA) na disciplina.

A AP1 e a AP2 contribuirão cada uma com $20 \%$ para o Cartão Virtual de Aprendizagens do estudante (CVA) na disciplina.

O estudante que no final da disciplina tiver o seu Cartão Virtual de Aprendizagens (CVA) com mais de 7.0 valores, será considerado aprovado na disciplina.

Tabela 2. Atividades de avaliação referentes ao cartão virtual de aprendizagem

Cartão Virtual de Aprendizagens do Estudante

$\begin{array}{lclcl}\text { Atividade } & \text { P-fólio 1 } & \text { Atividade } & \text { P-fólio 2 } & \text { T-fólio } \\ \text { Formativa } & 1 & \text { Formativa } & 2 & \\ \text { AF1 } & \text { PF 1 } & \text { AF2 } & \text { PF 2 } & \text { TF } \\ 50 \% & 50 \% & 50 \% & 50 \% & \\ \text { AP1 } & & \text { AP2 } & & \text { AP3 } \\ 20 \% & & 20 \% & & 60 \%\end{array}$

TOTAL $\quad 100 \%$

Fonte: Autoria própria

O desenvolvimento do projeto contempla a possibilidade de pedido de revisão de notas em um Fórum de pedido de revisão de notas

Esse espaço contempla dois momentos. Um em que para o colega que avaliou, o estudante deverá postar suas dúvidas e/ou insatisfações. Desse modo o estudante que avaliou poderá realizar a réplica às suas ponderações, mantendo ou alterando a nota.

Após esse momento as dúvidas e/ou insatisfações referentes à avaliação por colega, poderão ser submetidas ao professor, por intermédio de Fórum de pedido de revisão de notas. Essa submissão deverá seguir o procedimento idêntico ao referido anteriormente. Se esclarece que as dúvidas e/ou insatisfações referentes às notas, deverão ser apresentadas sempre em primeiro lugar ao colega. 


\section{Considerações finais}

?Adotar uma proposta de avaliação por pares em um curso a distância se revela bastante desafiador. ?A atividade de avaliação por pares tem revelado uma consolidação da ideia de uma comunidade de prática envolvendo os alunos no processo de aprendizagem e permitindo que os estudantes possam procurar em conjunto desenvolver a habilidade de avaliar o desempenho dos seus pares.

?A avaliação por pares tem como ideia central o referencial que que o conhecimento é construído a partir da interação entre alunos. Remete para a ideia de que os estudantes têm competências complementares que podem ensinar uns aos outroa. Aquele que avalia se beneficia igualmente quanto aquele que é avaliado. É uma poderosa ferramenta meta-cognitiva e o fato de a avaliação do par ser associada a um momento de auto-avaliação, possibilita não só desenvolver sua capacidade de refletir e avaliar criticamente seu próprio aprendizado, mas também em grupo refletir sobre seus próprios esforços, e estendem e enriquecem essa reflexão trocando comentários sobre o seu trabalho e o trabalho de seus pares. Apoia o desenvolvimento do pensamento crítico, habilidades interpessoais e outras, além de aprimorar a compreensão no campo do conhecimento de uma disciplina.

?Mecanismos de supervisão realizado pelo professor e também a oportunidade de apresentar argumentos que sustentem uma eventual alteração das notas atribuídas, tornam improvável qualquer tentativa de colusão ou inflação de grau. ?Desafios particulares se colocam aos indicadores,necessariamente específicos usados para avaliação dostrabalhos. A elaboração das rubricas dos indicadores, são por vezes consideradas mais difíceis do que escrever as perguntas de um exame. Os estudantes por vezes também ficam perplexos perante as instruções e o processo de avaliação por pares. Esse desafio foi ultrapassado pela disponibilização de vídeos que expliquem como a classificação de pares funciona.

?No desenvolvimento do estudo se buscará continuar a compreender a interação de docentes e estudantes com a proposta de Cartão Virtual de Avaliação das aprendizagens, bem como perceber de que modo ela poderá contribuir para o processo de avaliação da aprendizagem formativa.

\section{Referências bibliográficas}

CONWAY, R., KEMBER, D., SIVAN, A. and WU, M.. Peer assessment of an individual's contribution to a group project. Assessment \& Evaluation in Higher Education, 
18(1),1993. pp.45-56.

HALL, D. , BUZWELL, S.. The problem of free-riding in group projects: Looking beyond social loafing as reason for non-contribution. Active Learning in Higher Education, 2012. p.1469787412467123.

MACHADO, D. P.; QUADROS, D.; BENVENUTTI, C. D. Portfólio: tecendo saberes. Curitiba: Uninter, 2016.

VIANNA, Y. et al. Gamification, Inc: como reinventar empresas a partir de jogos. Rio de Janeiro: MJV Press, 2013. 